\title{
Novel Methodology Based on Biomimetic Superhydrophobic Substrates to Immobilize Cells and Proteins in Hydrogel Spheres for Applications in Bone Regeneration
}

\author{
Ana Catarina Lima, MSc, ${ }^{1,2}$ Patrícia Batista, MSc, ${ }^{3}$ Tiago A.M. Valente, MSc, ${ }^{3}$ \\ A. Sofia Silva, MSc, ${ }^{3}$ llídio J. Correia, $\mathrm{PhD},{ }^{3}$ and João F. Mano, $\mathrm{PhD}^{1,2}$
}

Cell-based therapies for regenerative medicine have been characterized by the low retention and integration of injected cells into host structures. Cell immobilization in hydrogels for target cell delivery has been developed to circumvent this issue. In this work mesenchymal stem cells isolated from Wistar rats bone marrow (rMSCs) were immobilized in alginate beads fabricated using an innovative approach involving the gellification of the liquid precursor droplets onto biomimetic superhydrophobic surfaces without the need of any precipitation bath. The process occurred in mild conditions preventing the loss of cell viability. Furthermore, fibronectin (FN) was also immobilized inside alginate beads with high efficiency in order to mimic the composition of the extracellular matrix. This process occurred in a very fast way (around $5 \mathrm{~min}$ ), at room temperature, without aggressive mechanical strengths or particle aggregation. The methodology employed allowed the production of alginate beads exhibiting a homogenous rMSCs and FN distribution. Encapsulated rMSCs remained viable and were released from the alginate for more than 20 days. In vivo assays were also performed, by implanting these particles in a calvarial bone defect to evaluate their potential for bone tissue regeneration. Microcomputed tomography and histological analysis results showed that this hybrid system accelerated bone regeneration process. The methodology employed had a dual role by preventing cell and FN loss and avoiding any contamination of the beads or exchange of molecules with the surrounding environment. In principle, the method used for cell encapsulation could be extended to other systems aimed to be used in tissue regeneration strategies.

\section{Introduction}

$\mathbf{M}$ ESENChyMal STEM Cells (MSCs) due to their multipotent properties and high rate of proliferation have been studied for regenerative medicine strategies. ${ }^{1,2}$ When cultured under specific environments and appropriated supplemented culture media, MSCs can differentiate into lineages of mesenchymal tissues such as bone, cartilage, fat, muscle, tendon, and marrow stroma. ${ }^{3}$

Hydrogels have been used as carrier's materials to specifically deliver cells directly into damaged tissues, thus avoiding cell loss through the blood stream. ${ }^{1,4-6}$ The highly hydrated microenvironment and similar structure to the extracellular matrix (ECM) of these carriers provide good permeability for low molecular weight solutes, such as metabolites, nutrients, or other bioactive molecules that can present biochemical, cellular, and physical stimuli for cell differentiation, prolifer- ation, and migration. ${ }^{7}$ The cells immobilized inside hydrogels are physically isolated and consequently protected from the deleterious outside environment. ${ }^{8-11}$ Although other shapes can be employed, spheres have been the most explored due to their large surface area, the ability to immobilize greater amount of biologically active molecules, or cells per unit volume $^{12}$ and due to the possibility of application in most complex systems such as cell-induced aggregates, cell carriers for cell expansion, and organ printing. ${ }^{13}$

Several polysaccharides have been proposed as biomaterials for tissue engineering and regenerative medicine. ${ }^{14}$ The vast majority of them, such as alginate, are currently used in the form of hydrogels to create structures with size features ranging between 0.1 and $10 \mathrm{~mm} .{ }^{15}$ MSCs encapsulated in alginate hydrogels have been reported in the literature for different applications, such as bone ${ }^{15}$ and cartilage regeneration, ${ }^{16}$ angiogenesis, ${ }^{17}$ and tumor treatment. ${ }^{18}$ The easy gelling and

\footnotetext{
${ }^{1} 3$ B's Research Group-Biomaterials, Biodegradables and Biomimetics, Headquarters of the European Institute of Excellence on Tissue Engineering and Regenerative Medicine, University of Minho, Guimarães, Portugal.

${ }^{2} \mathrm{ICVS} / 3 \mathrm{~B}$ 's—PT Government Associate Laboratory, Guimarães, Portugal.

${ }^{3}$ CICS-UBI-Centro de Investigação em Ciências da Saúde, Faculdade de Ciências da Saúde, Universidade da Beira Interior, Covilhã, Portugal.
} 
biocompatible properties of alginate hydrogels, obtained by ionic crosslinking, have led to their study as cell transplantation vehicles for tissue regeneration. ${ }^{19}$ However, since alginatebased hydrogels poorly bind serum proteins, different ECM compounds such as fibronectin (FN), ${ }^{20}$ collagen, ${ }^{16,21}$ or RGD sequences ${ }^{22,23}$ have been added to these polysaccharides in order to offer adhesion sites to mammalian cells.

So far, the techniques used for cell immobilization inside hydrogels required the mixing of gelling precursor with cells, followed by gelation through a physical, chemical, or ionic crosslinking. Several technologies have been proposed for cell immobilization in hydrogel particles, and some of them adopted from methodologies used in the pharmaceutical industry ${ }^{24,25}$ : emulsification, photolithography, microfluidics, or coagulation baths using special dispensing systems of cell suspension in polymeric solutions. However, a significant part of these methodologies imply the contact of the gelling phase containing the cells or bioactive molecules with another liquid phase, which may be responsible for cells or molecules loss, due to their diffusion from the gel to the supporting liquid. The uncontrolled entrance of solvents may also lead to the contamination of the forming hydrogels, which may compromise the viability of the cells entrapped inside the matrix. In this work an innovative methodology involving the use of superhydrophobic substrates ${ }^{26}$ was employed to produce spherical hydrogels able to immobilize cells and bioactive compounds with high efficiency. The major advantages of this procedure include the use of mild processing conditions, high encapsulation loading, lower production costs, control of the particle size, and absence of mechanical forces during particles formation. This methodology has already been validated for production of controlled drug delivery systems. ${ }^{27}$ We hypothesize that the method could be adapted to be used to encapsulate MSCs in hydrogel spheres containing bioactive molecules for posterior use in bone tissue engineering strategies. In vitro studies were performed to analyze the effect of the immobilization method on cell viability and also to evaluate cell differentiation over time. After that, in vivo studies were also performed to characterize the applicability of this system for bone tissue regeneration.

\section{Materials and Methods}

\section{Materials}

Polystyrene (PS) from a grade for injection molding was used in a granular shape for the preparation of the superhydrophobic substrates. Tetrahydrofuran (THF, $99.9 \%$ ) was purchased from Riedel de-Haen. $1 \mathrm{H}, 1 \mathrm{H}, 2 \mathrm{H}, 2 \mathrm{H}-$ perfluorodecyltriethoxysilane (PFDTS, 97\%), low-viscosity sodium alginate (ALG), FN from human plasma, Dulbecco's modified Eagle's medium (DMEM-F12), trypsin, albumin bovine serum (BSA, 96\%), 4,6-diamidino-2-phenyindole, dilactate (DAPI), tetramethylrhodamine B isothiocyanate (Phalloidin), and in vitro toxicology assay kit (lactate dehydrogenase [LDH] quantification) were purchased from SigmaAldrich. Ethanol was purchased from Panreac. Calcium chloride $\left(\mathrm{CaCl}_{2}\right)$ was purchased from Merck. Fetal bovine serum (FBS) was purchased from Biochrom AG. 3-[4,5dimethylthiazol-2-yl]-5-(3-carboxy-methoxyphenyl)-2-(4sulfophenyl)-2H-tetrazolium, inner salt (MTS) and electron coupling reagent (phenazine methosulfate; PMS) were pur- chased from Promega. FN was labeled using Molecular Probes' Alexa Fluor 555 Protein Labeling kit and cells were labeled with Hoechst 33342 and calcein acetoxymethyl ester (calcein-AM) purchased from Invitrogen. Propidium iodide (PI) was purchased from VWR. Hydrochloric acid solution was purchased from Surgipath. All chemicals were used as received.

\section{Methods}

PS superhydrophobic surfaces. PS superhydrophobic surfaces were prepared using a phase separation method as described elsewhere. ${ }^{26,27}$ Briefly, a PS solution $(70 \mathrm{mg} / \mathrm{mL})$ in THF was prepared and then mixed with ethanol $(2: 1.3 \mathrm{v} / \mathrm{v})$. The mixture was dispensed onto smooth PS commercial substrate, which was then immersed in ethanol for $1 \mathrm{~min}$ and dried with nitrogen flow. In order to increase the superhydrophobicity of obtained surfaces, the rough PS surfaces were modified with PFDTS ( $1 \% \mathrm{v} / \mathrm{v}$ in ethanol) after argon plasma treatment for $40 \mathrm{~s}$ at $30 \mathrm{~W}$ (Plasma Prep5; Gala Instruments).

Preparation of the hydrogel particles. The beads were produced using different ALG concentrations: 1\%, 1.5\%, and $2 \%(\mathrm{w} / \mathrm{v})$. Five microliters of ALG solution were dispensed on the PS superhydrophobic surface. The alginate hydrogel beads were obtained on the surface after addition of $2 \mu \mathrm{L}$ of $5 \%(\mathrm{w} / \mathrm{v}) \mathrm{CaCl}_{2}$ solution on the top of each liquid sphere.

Stability of the alginate particles in culture medium. The stability of the produced beads was analyzed through quantification of calcium released from crosslinked alginate beads immersed in cell culture medium. Five alginate beads of each concentration were placed in $5 \mathrm{~mL}$ of cell culture medium $(n=3)$ : DMEM-F12 supplemented with FBS $(10 \%$, $\mathrm{v} / \mathrm{v})$, penicillin $\mathrm{G}\left(100 \mathrm{U} / \mathrm{cm}^{3}\right)$, streptomycin $\left(100 \mu \mathrm{g} / \mathrm{cm}^{3}\right)$, and amphotericin $\mathrm{B}\left(0.25 \mu \mathrm{g} / \mathrm{cm}^{3}\right)$. The vials containing the beads were kept at $37^{\circ} \mathrm{C}$. At pre-established periods of time, aliquots of $1 \mathrm{~mL}$ of the supernatant were taken out and replaced with equal volume of fresh cell culture medium to maintain the volume constant during the release study. The calcium concentration of the collected samples was measured using Coupled Plasma Spectrometry (ICP, JY 2000-2; Horiba Jobin Yvon), after diluted $10 \times$ in $1 \% \mathrm{HNO}_{3}(\mathrm{v} / \mathrm{v})$ solution.

Cell culture and immobilization in alginate beads. MSCs from Wistar rats femoral bone marrow ${ }^{28,29}$ were isolated as previously described. ${ }^{30}$ Then, cells were seeded in T-flasks with DMEM-F12 supplemented with FBS $(10 \% \mathrm{v} / \mathrm{v})$, penicillin G $\left(100 \mathrm{U} / \mathrm{cm}^{3}\right)$, streptomycin $\left(100 \mu \mathrm{g} / \mathrm{cm}^{3}\right)$, and amphotericin B $\left(0.25 \mu \mathrm{g} / \mathrm{cm}^{3}\right)$. rMSCs were kept in culture inside an incubator at $37^{\circ} \mathrm{C}$ with a $5 \% \mathrm{CO}_{2}$ humidified atmosphere. After reached confluence, rMSCs were subcultivated by a $3-5 \mathrm{~min}$ incubation in $0.18 \%$ trypsin $(1: 250)$ and $5 \mathrm{mM}$ ethylenediaminetetraacetic acid. Subsequently, the rMSCs were centrifuged, resuspended in culture medium, and then encapsulated in alginate beads. Cells were added to $1,1.5$, and $2 \mathrm{wt} \%$ alginate solutions in order to obtain $\sim 10,000$ cells/bead. Some studies were carried out in the presence of FN. In those cases, FN with a concentration of $250 \mu \mathrm{g} / \mathrm{mL}^{31}$ was added to alginate cell suspension. Five microliters of cell suspension with or without FN was 


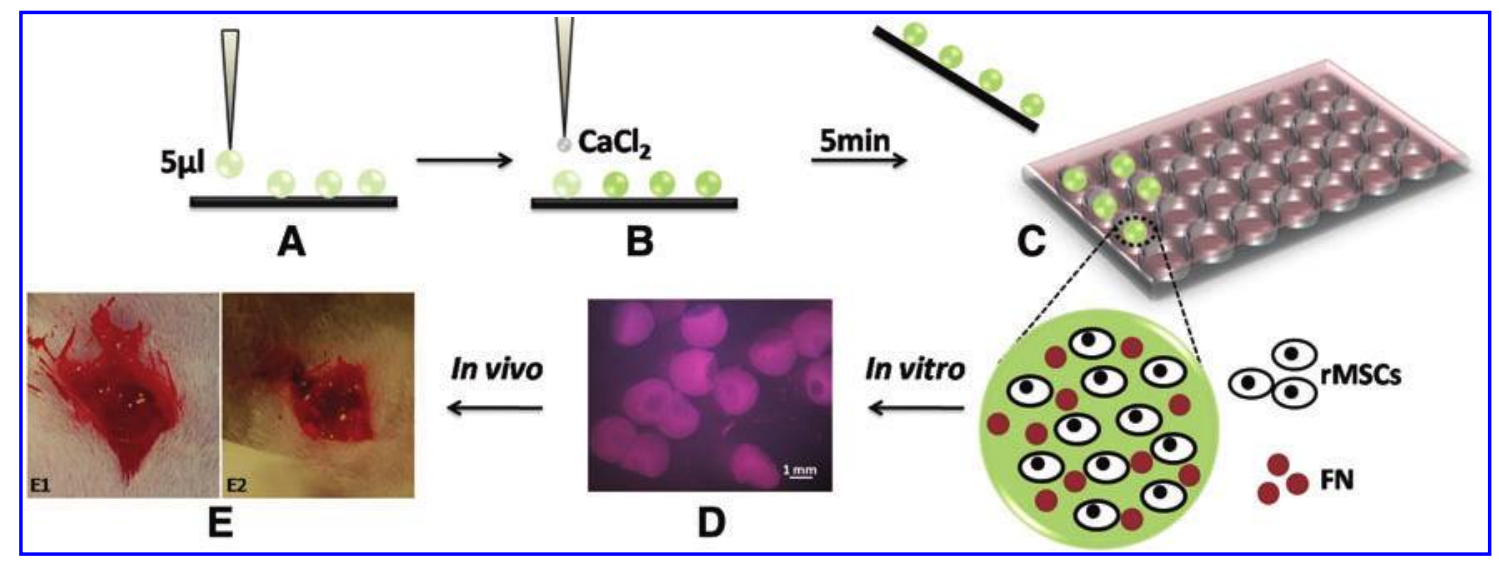

FIG. 1. Schematic representation of cell and protein immobilization in alginate hydrogels using polystyrene (PS) superhydrophobic substrates: $5 \mu \mathrm{L}$ drops of mesenchymal stem cells isolated from Wistar rats bone marrow (rMSCs) + fibronectin (FN) suspension in a sodium alginate (ALG) solution were dispensed on PS superhydrophobic substrates (A). $\mathrm{After}, 2 \mu \mathrm{L}$ of $\mathrm{CaCl}_{2}$ was dispensed on the top of each drop to crosslink alginate (B). After 5 min the spheres with rMSCs + FN immobilized were collected (C) and in vitro (D) and in vivo (E) tests were performed. A bone defect was created in calvarial bone (E1) and filled in with particles (E2) in order to evaluate the regeneration of the bone. Color images available online at www .liebertpub.com/tea

dispensed on the PS superhydrophobic surface (Fig. 1A). The alginate hydrogel beads were obtained on the surface after addition of $2 \mu \mathrm{L}$ of $5 \%(\mathrm{w} / \mathrm{v}) \mathrm{CaCl}_{2}$ solution on the top of each sphere (Fig. 1B). After that, the spheres were kept in culture with $150 \mu \mathrm{L}$ of cell culture medium (Fig. 1C).

The distribution of FN in alginate beads was observed by fluorescent microscopy (Zeiss) using $250 \mu \mathrm{g} / \mathrm{mL}$ of FN labeled with Alexa Fluor 555 dye following the protocol of Molecular Probe's Alexa Fluor 555 Protein Labeling kit.

Phalloidin and DAPI staining to visualize actin cytoskeleton and to label the DNA, respectively, were conducted as outlined by the supplier's protocol. Briefly, the particles were washed with $0.15 \mathrm{M}$ of $\mathrm{NaCl}$ supplemented with $10 \mathrm{mM}$ of $\mathrm{CaCl}_{2}$, fixed in freshly prepared $4 \%(\mathrm{v} / \mathrm{v})$ of formaldehyde in phosphate-buffered saline for $15 \mathrm{~min}$ at room temperature (RT), and washed extensively to remove all traces of the fixative. The cells were then stained with $50 \mu \mathrm{g} / \mathrm{mL}$ fluorescent phalloidin for $45 \mathrm{~min}$ at RT. DAPI labeling solution $(0.5 \mu \mathrm{g} / \mathrm{mL})$ was incubated for $3 \mathrm{~min}$ at $\mathrm{RT}$. The particles were washed again to remove remaining staining solutions and visualized using a Zeiss LSM 710 confocal microscope equipped with a $10 \times / 0.5$ dry Fluor objective (Carl Zeiss SMT, Inc.).

Beads distribution size was investigated using a stereo microscope (Stemi 1000 PG-HITECH; Zeiss). After being prepared, alginate beads were immersed in cell culture media and observed under stereomicroscope immediately. The mean particle size was calculated by analyzing the images using the ImageJ software.

In vitro live/dead assay. rMSCs immobilized in alginate beads were kept in culture, in a 96-well plate, with $150 \mu \mathrm{L}$ of DMEM-F12 supplemented with FBS $(10 \%$, v/v), penicillin G $\left(100 \mathrm{U} / \mathrm{cm}^{3}\right)$, streptomycin $\left(100 \mu \mathrm{g} / \mathrm{cm}^{3}\right)$, and amphotericin B $\left(0.25 \mu \mathrm{g} / \mathrm{cm}^{3}\right)$ and incubated at $37^{\circ} \mathrm{C}$, with a $5 \% \mathrm{CO}_{2}$ humidified atmosphere. After an incubation period of 24,48 , and $72 \mathrm{~h}$, cells viability was assessed through the reduction of the MTS into a water-soluble formazan product. ${ }^{32}$ Briefly, the medium of each well was removed and replaced with a mixture of $100 \mu \mathrm{L}$ of fresh culture medium and $20 \mu \mathrm{L}$ of MTS/PMS reagent solution. Then, the beads were incubated for $4 \mathrm{~h}$ at $37^{\circ} \mathrm{C}$. The absorbance was measured at $492 \mathrm{~nm}$ using a microplate reader (Sanofi; Diagnostics Pauster). Wells containing cells in the culture medium without being immobilized in alginate were used as negative controls $\left(\mathrm{K}^{-}\right)$. $\mathrm{EtOH}(96 \%)$ was added to wells with cells, to be used as a positive control $\left(\mathrm{K}^{+}\right) \cdot{ }^{32}$ Moreover, the amount of dead cells was also quantified by the LDH assay, in $2 \% \mathrm{ALG}+\mathrm{FN}$ particles due to the higher beads stability. $\mathrm{LDH}$ is released to the medium through the damaged cell membrane and convert a yellow tetrazolium salt into a red formazan dye, which is quantified by reading its absorbance at $492 \mathrm{~nm}$ using a microplate reader. The optical density is proportional to the number of lysed cells. ${ }^{33}$ After 24, 48, and $72 \mathrm{~h}$ the well plates containing the beads in culture were shaken briefly to homogenize the released LDH into the cell culture medium. Then, $50 \mu \mathrm{L}$ of the cell culture medium was transferred into a fresh 96-well plate and $100 \mu \mathrm{L}$ of $\mathrm{LDH}$ assay mixture was added to each well. ${ }^{34}$ After $30-45$ min the enzymatic activity was stopped by adding $7.5 \mu \mathrm{L}$ of $\mathrm{HCl}$ and the absorbance was measured. Wells containing cells in the culture without being immobilized in alginate were used as negative control and lysis solution was added to wells containing cells as a positive control. The results obtained were expressed as the mean \pm the standard error of the mean for at least three independent experiments.

Live/dead staining was also performed on $2 \%$ ALG $+\mathrm{FN}$ particles. The beads were incubated for $15 \mathrm{~min}$ at $37^{\circ} \mathrm{C}$ and immersed in $0.15 \mathrm{M}$ of $\mathrm{NaCl}$ complemented with $10 \mathrm{mM}$ of $\mathrm{CaCl}_{2}$ where $2 \mu \mathrm{L}$ of Calcein $\mathrm{AM}(1 \mathrm{mg} / \mathrm{mL})$ and $1 \mu \mathrm{L}$ of PI $(1 \mathrm{mg} / \mathrm{mL})$ were added. After incubation, the Calcein AM/ PI solution was removed and the beads were washed and finally visualized in a Zeiss LSM 710 confocal microscope with appropriated filters to detect green (live cells) and red (dead cells).

Cell morphology: light microscopy, scanning electron microscopy, and fluorescent microscopy. rMSC morphology, 
Table 1. Mean Size of the Produced Beads $(N=6)$ Obtained Using Different Alginate Concentrations

\begin{tabular}{lc}
\hline Beads formulation & Beads size $(\mu \mathrm{m})$ \\
\hline $1 \%$ ALG & $1930 \pm 160$ \\
$1.5 \%$ ALG & $2030 \pm 190$ \\
$2 \%$ ALG & $2180 \pm 160$ \\
\hline
\end{tabular}

ALG, sodium alginate.

adhesion, and proliferation were firstly visualized using an Olympus CX41 inverted light microscope, equipped with an Olympus SP-500 UZ digital camera.

Scanning electron microscopy (SEM) was also used to observe the morphology of the rMSCs immobilized in the alginate particles. To do so, samples were fixed overnight using $2.5 \%$ glutaraldehyde in water, at $4^{\circ} \mathrm{C}$. After that, they were rinsed with distilled water and dehydrated in graded ethanol of $70 \%, 80 \%, 90 \%$, and $100 \%$ for $10 \mathrm{~min}$ each. Finally, the samples were mounted in supports using double-size adhesive tape and coated with gold by using Emitech K550 sputter coater. Samples were analyzed using a Hitachi S-2700 SEM.

Moreover, to visualize the rMSCs immobilized in alginate, a Hoechst dye (H1399) was used to label cell nucleus. A trihydrochloride trihydrate solution $(2 \mu \mathrm{g} / \mathrm{mL})$ was added to a cell pellet obtained by centrifugation and then resuspended in culture media. After $30 \mathrm{~min}$ in contact with Hoechst solution, rMSCs were encapsulated in alginate in the same conditions as previously described. rMSCs were visualized after $0,24,48$, and $72 \mathrm{~h}$ of incubation in a Zeiss AX10 microscope and analyzed with the Axio Vision Real 4.6 software (Carl Zeiss SMT, Inc.).

Osteogenic induction. To induce osteogenic differentiation, rMSCs immobilized in alginate beads were cultured in osteogenic medium, which consisted on DMEM-F12 containing FBS $(10 \%, \mathrm{v} / \mathrm{v})$, penicillin $\mathrm{G}\left(100 \mathrm{U} / \mathrm{cm}^{3}\right)$, streptomycin $\left(100 \mu \mathrm{g} / \mathrm{cm}^{3}\right)$, amphotericin B $\left(0.25 \mu \mathrm{g} / \mathrm{cm}^{3}\right)$, and supplemented with $0.1 \mathrm{mM}$ L-ascorbic acid 2-phosphate, $10 \mathrm{mM}$ beta-glycerol phosphate, and $100 \mathrm{nM}$ dexamethasone. ${ }^{35}$ At $1,7,14$, and 21 days postinduction, alginate beads were fixed overnight in $2.5 \%$ glutaraldehyde in water, at $4^{\circ} \mathrm{C}$, dehydrated in graded ethanol solutions, and finally embedded in paraffin blocks. Sections of $4-5 \mu \mathrm{m}$ were stained with alizarin red dye for the detection of calcium deposits. Microscope images were acquired with Zeiss Imager A.1.
In vivo assays. The in vivo experiments were performed using 12 Wistar rats with an average weight of $200 \mathrm{~g}$. Such studies were done accordingly to the guidelines set forth in the National Institutes of Health Guide for the care and use of laboratory animals. Animals were anesthetized by intraperitoneal injection of ketamine $(40 \mathrm{mg} / \mathrm{kg}$ ) and xylazine $(5 \mathrm{mg} /$ $\mathrm{kg}$ ). Bone defects with $\sim 5 \mathrm{~mm}$ diameter were made on calvarial bone and four beads with $\sim 10,000$ rMSCs and FN $(250 \mu \mathrm{g} / \mathrm{mL})$ were implanted inside it. The alginate concentration with best results in vitro was selected to be tested in animals ( $2 \%$ ALG). For that, three groups $(n=4)$ were created: (1) controls with empty defects; (2) alginate beads just with FN were implanted; and (3) an experimental group where alginate beads with FN and immobilized rMSCs were implanted. After its implantation into bone defects, animals were maintained in individual cages with free access to commercial rat food and water ad libitum. Then, animals were euthanized after 4 weeks with an overdose of anesthetic.

Microcomputed tomography: Cranial bone samples obtained at week 4 by necropsy were fixed in formaldehyde. After dehydration, the samples were analyzed using a highresolution microcomputed tomography $(\mu \mathrm{CT})$ Skyscan 1072 scanner (Skyscan). Scannings were performed in highresolution mode using a pixel size of $14.7 \mu \mathrm{m}$ and integration time of $1.7 \mathrm{~s}$. The X-ray source was set at $51 \mathrm{kV}$ of energy and $195 \mu \mathrm{A}$ of current. For all samples, representative data sets were transformed into binary using a dynamic threshold of 42-255. This data was used for morphometric analysis (CT Analyzer v1.5.1.5; SkyScan). Three-dimensional (3D) virtual models of calvarial bones were created, visualized, and registered using the image-processing software (ANT 3D creator v2.4; SkyScan).

Histology: Cranial bones samples used for $\mu \mathrm{CT}$ analysis were then decalcified in a hydrochloric acid solution and embedded in paraffin blocks. Furthermore, sample organs (brain, heart, lung, liver, spleen, and kidney) were also collected, fixed in formaldehyde, and embedded in paraffin blocks for routine histological processing in order to check for any morphological alteration. Sections of $4-5 \mu \mathrm{m}$ were stained with hematoxylin and eosin and finally visualized using a light microscope (Zeiss Imager A.1).

Statistical analysis. Statistical analysis (GraphPad Prism; GraphPad Software) concerning MTS and LDH assays was performed using one-way analysis of variance following the
FIG. 2. Fluorescent microscopy images of FN $(250 \mu \mathrm{g} / \mathrm{mL})$ labeled with Alexa Fluor 555 (A) and rMCSs labeled with Phalloidin/ DAPI (B) inside 2\% ALG beads. DAPI, 4,6-diamidino-2phenylindole. Color images available online at www .liebertpub.com/tea
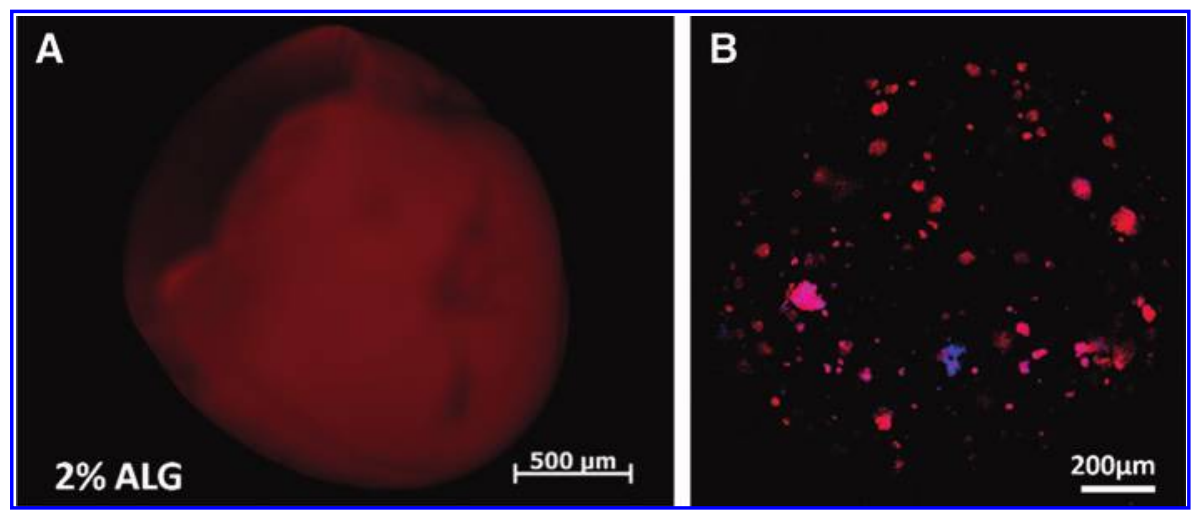


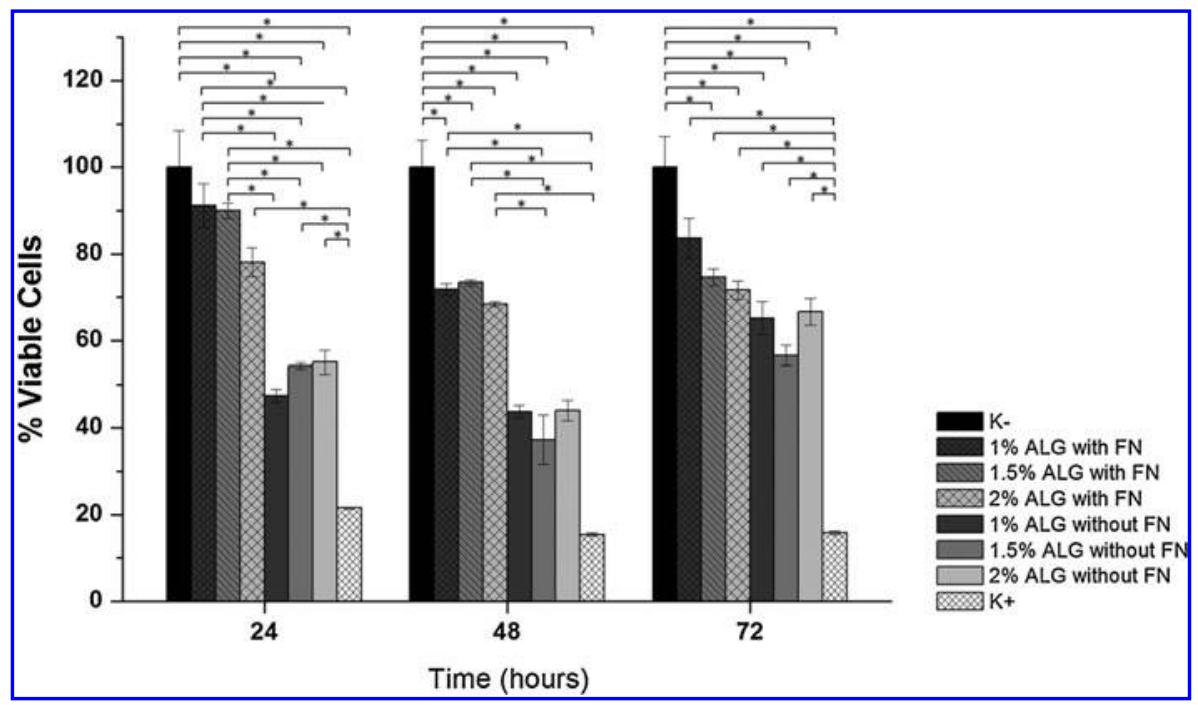

FIG. 3. Cellular activity quantified by MTS assay: $\left(\mathrm{K}^{-}\right)$, negative control where cells were cultivated in wells; $\left(\mathrm{K}^{+}\right)$, positive control where the cells were dead and rMSCs immobilized in three different alginate concentrations with and without FN. Each result is the mean and respective standard error of at least three independent experiments.

Tukey's post-hoc test with a significant set at $p<0.05$. All the results are presented as the mean \pm standard deviation.

\section{Results and Discussion}

\section{rMSC and FN immobilization in alginate beads}

Cell encapsulation is an important strategy to prevent the escape and the elimination of the entrapped cells when implanted in damaged tissue sites. ${ }^{18}$ The most important objective of this work was the evaluation of the applicability of superhydrophobic surfaces as a method to immobilize cells (rMSCs previously isolated from Wistar rats) and unstable molecules (as it is the case of proteins and glycoproteins, such as FN) inside spherical hydrogels to be used in tissue engineering purposes (see Fig. 1). The water-repellent properties of PS superhydrophobic surfaces allowed the production of nearly spherical shape hydrophilic particles (Fig. 1D). Different concentrations of alginate in the liquid precursors were used $(1 \%, 1.5 \%$, and $2 \% \mathrm{w} / \mathrm{v})$. The final diameter of the obtained beads tended to increase with increasing alginate concentration, despite the same volume of the precursor solution was used (see Table 1). As an innovative method- ology capable to immobilize mammalian cells and proteins, superhydrophobic surfaces show several advantages when compared with traditional techniques. For example, some of those methodologies to produce polymeric particles have a spread particle size distribution, ${ }^{36}$ which constitutes a problem when a narrow range of sizes is required. As it is possible to verify in the obtained results, the particles produced using superhydrophobic surfaces own a narrow size distribution, highly controlled by the volume of the liquid precursors dispensed over the substrates. This volume control could be interesting to produce particles with a specific required size. In addition, the small range of particle size obtained avoids additional steps for particle selection, saving production time and costs. The absence of mechanical forces that are sometimes responsible for cell damage and loss of biological activity of molecules constitutes another advantage of this methodology.

The dry environment where droplets harden into hydrogels avoids the particle aggregation and provide very high encapsulation efficiency (almost 100\%) because cells or bioactive molecules are not in contact with surrounding fluid media and they cannot migrate or diffuse outside the volume

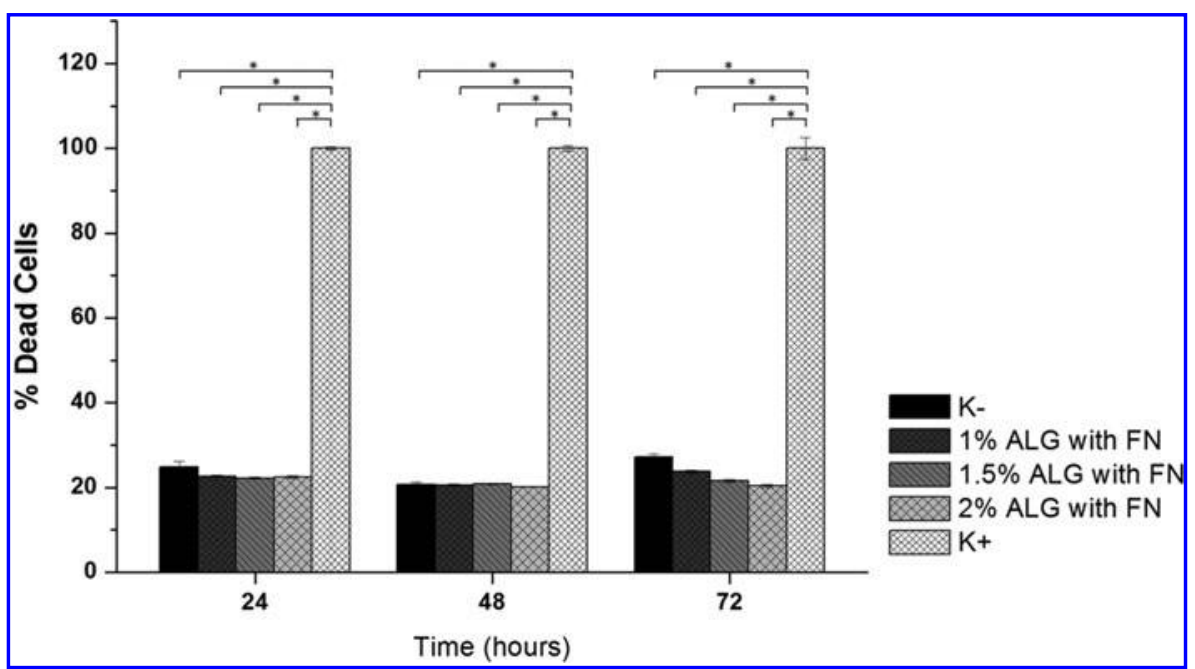

FIG. 4. LDH quantification of rMSCs immobilized in alginate beads with FN in culture after 24, 48 , and $72 \mathrm{~h}:\left(\mathrm{K}^{-}\right)$is the negative control where cells were cultivated in wells; $\left(\mathrm{K}^{+}\right)$is the positive control where the cells were dead. LDH, lactate dehydrogenase. 

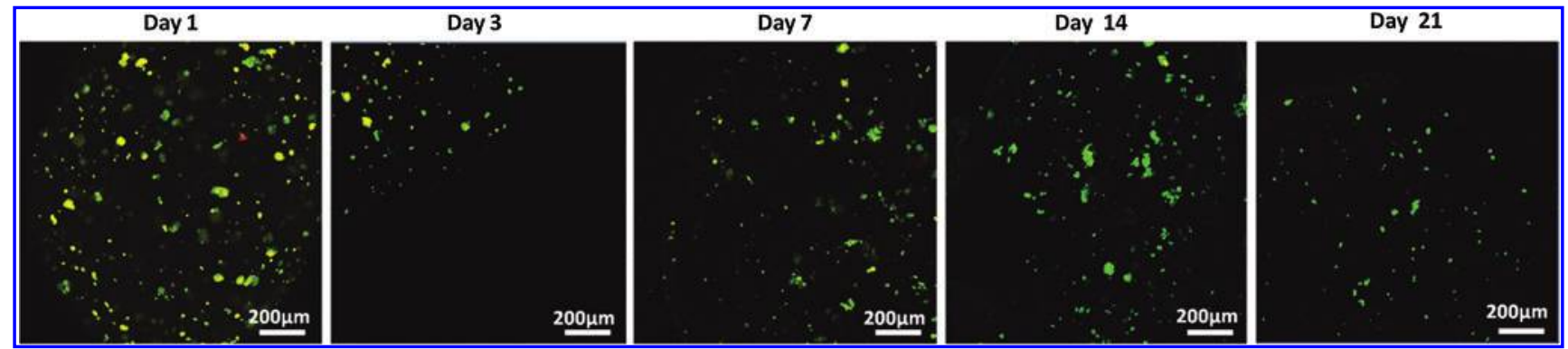

FIG. 5. Live/dead staining of rMSCs immobilized into $2 \%$ ALG +FN beads over 21 days in culture. Color images available online at www.liebertpub.com/tea

of the spherical objects. This is particularly useful because FN molecules are water soluble, ${ }^{37}$ which is a bottleneck of the encapsulation procedures previously described in literature, ${ }^{24}$ since water-soluble molecules are easily lost to the wet media commonly used in those techniques. Moreover, this characteristic is particularly important when expensive molecules such as growth factors, or even genes, are desired to be encapsulated. Compared with other immobilization techniques, superhydrophobic surfaces allowed a very fast particle production because the particles became completely solid within the time of the cross-linking reaction, usually a fast chemical or physical process.

The results obtained show (Fig. 2A, B) that FN molecules and cells were homogenously distributed on the beads, in agreement to our previous work, where BSA labeled with fluorescein isothiocyanate was encapsulated in dextran/ poly(N-isopropylacrylomide (PNIPAAm) beads as a model drug. ${ }^{27}$ The three studied formulations exhibited similar FN and rMSC distribution (data not showed). To our knowledge, the co-encapsulation of FN and rMSCs in alginate hydrogels for bone regeneration applications was never studied before.

\section{In vitro alginate cytotoxicity and rMSC morphology studies}

The synergistic effect of FN in cell viability was first explored quantitatively through cytotoxicity evaluation. Figure 3 shows MTS assay results and a significant difference between encapsulated cells and positive controls (dead cells), both in the presence and in the absence of FN, for 24, 48 , and $72 \mathrm{~h}$ was observed. This means that the material is noncytotoxic and the rMSCs maintain their viability for at least 3 days. The general decrease in cell viability observed between 24 and $48 \mathrm{~h}$ for all alginate formulations may be explained by the need of an accommodation period by the rMSCs to adapt to new conditions. After this period the cell viability remains constant. ${ }^{38}$

When compared the amount of viable cells immobilized in the presence or absence of FN, it is possible to observe that in the first $48 \mathrm{~h}$ of culture, there is a significant difference between both conditions. This difference was attenuated after $72 \mathrm{~h}$, indicating that the effect of FN was more relevant in the initial anchorage of the cells in the hydrogel structure. The fraction of viable cells was higher in the presence of FN for all alginate formulations ( $1 \%, 1.5 \%$, and $2 \%$ ALG) (Fig. 3$)$. It is well known that FN is an ECM constituent with a relevant role in regulation of cell adhesion, proliferation, and differentiation, ${ }^{39}$ which are very important factors for osteogenesis of human $\mathrm{MSCs}^{21}$ as also that FN presence in the plasma modulates the response of the body against new implanted biomaterials constituting a good strategy to improve the performance of biomedical devices. ${ }^{40}$ Having this into account, the entrapment of FN in alginate beads, beyond contributing to increase cell viability should also improve the acceptance of the studied system in vivo.

To further characterize the carrier's biocompatibility and corroborate the MTS results, LDH assay was also performed in the particles with FN and the corresponding fraction of dead cells is shown in Figure 4. LDH is a stable cytoplasmatic enzyme that is released to the extracellular media when the cytoplasmatic membrane is damaged being directly proportional to the percentage of dead cells. ${ }^{33}$ Figure 4 shows that during at least $72 \mathrm{~h}$ the percentage of dead rMSCs encapsulated in alginate were maintained around $20 \%-25 \%$, which is similar to the value obtained for the negative control (normal cell culture).

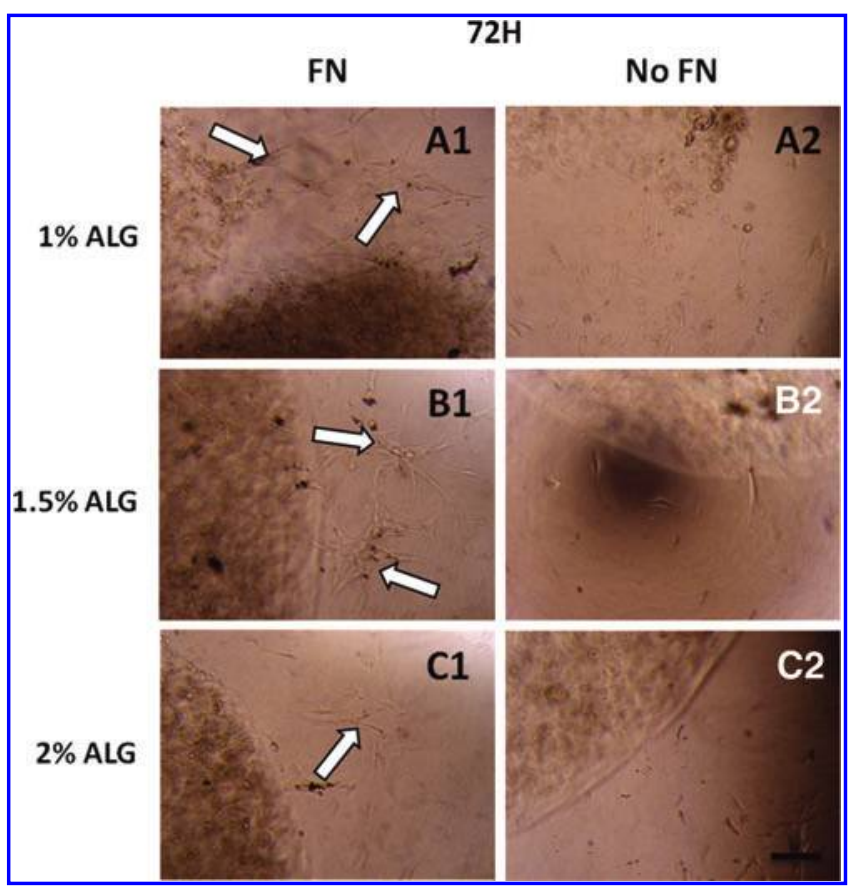

FIG. 6. Optical microscopy images of alginate particles loaded with rMSCs. Group A were beads composed by 1\% ALG after $72 \mathrm{~h}$ in culture in presence (A1) and absence (A2) of FN. The same order of images disposition was followed for the other alginate beads concentration: in group B was 1.5\% ALG and group C $2 \%$ ALG. The white arrows show the cells released due to the slight particle disintegration. Scale bar $20 \mu \mathrm{m}$. Color images available online at www.liebertpub.com/tea 
Finally, the distribution of the live and dead rMSCs inside the $2 \%$ ALG + FN (the most stable formulation) particles was accessed by calcein-AM/PI staining for 21 days of culture. As it is possible observe in Figure 5, the majority of the cells were green which means that were live and significant differences were not observed over time. The beads provided good conditions for rMCS survival and representative confocal microscopy images are observed in Figure 5. Regarding the fraction of viable cells inside our alginate beads, similar results were previously obtained by Zhao et al. ${ }^{41}$ for human umbilical cord stem cell encapsulated in alginate, where the percentage of viable cells ranged from $\sim 90 \%$ to $70 \%$, after 7 days of culture.

Figure 6 presents optical microscopy images of beads with different alginate concentrations in the presence and absence of FN after $72 \mathrm{~h}$ in culture. After 1 day the cells were seen well confined in the volume of the beads. Over 3 days in culture, rMSCs remained with their typically round shape and were homogeneously distributed inside the alginate beads. However, at this time point, it was possible to detect a slight particle disintegration and the consequently cell release (white arrows in Fig. 6) principally in weaker beads corresponding to the ones prepared with lower alginate concentrations. The released rMSCs migrated from the particle core to the surface, adhered in the wells, and probably the proliferation started. The referred continuous cell release and proliferation was accessed and followed by optical microscopy for more 18 days in all alginate concentrations even after beads transferring to new well plates (see images in Fig. 7 ). The $1 \%$ ALG beads released a higher number of rMSCs when compared to that of $1.5 \%$ and $2 \%$ ALG, for the same period. Such finding can be explained by the alginate particle disintegration, which occurred at higher rate for low concentration alginate beads. Similar results were earlier reported by Hunt et al. ${ }^{42}$ They studied the degradation of $2 \%$ and $5 \% \mathrm{w} / \mathrm{v}$ alginate matrix with immobilized fibroblasts under normal cell culture conditions where it was shown that the alginate degradation process was not influenced by

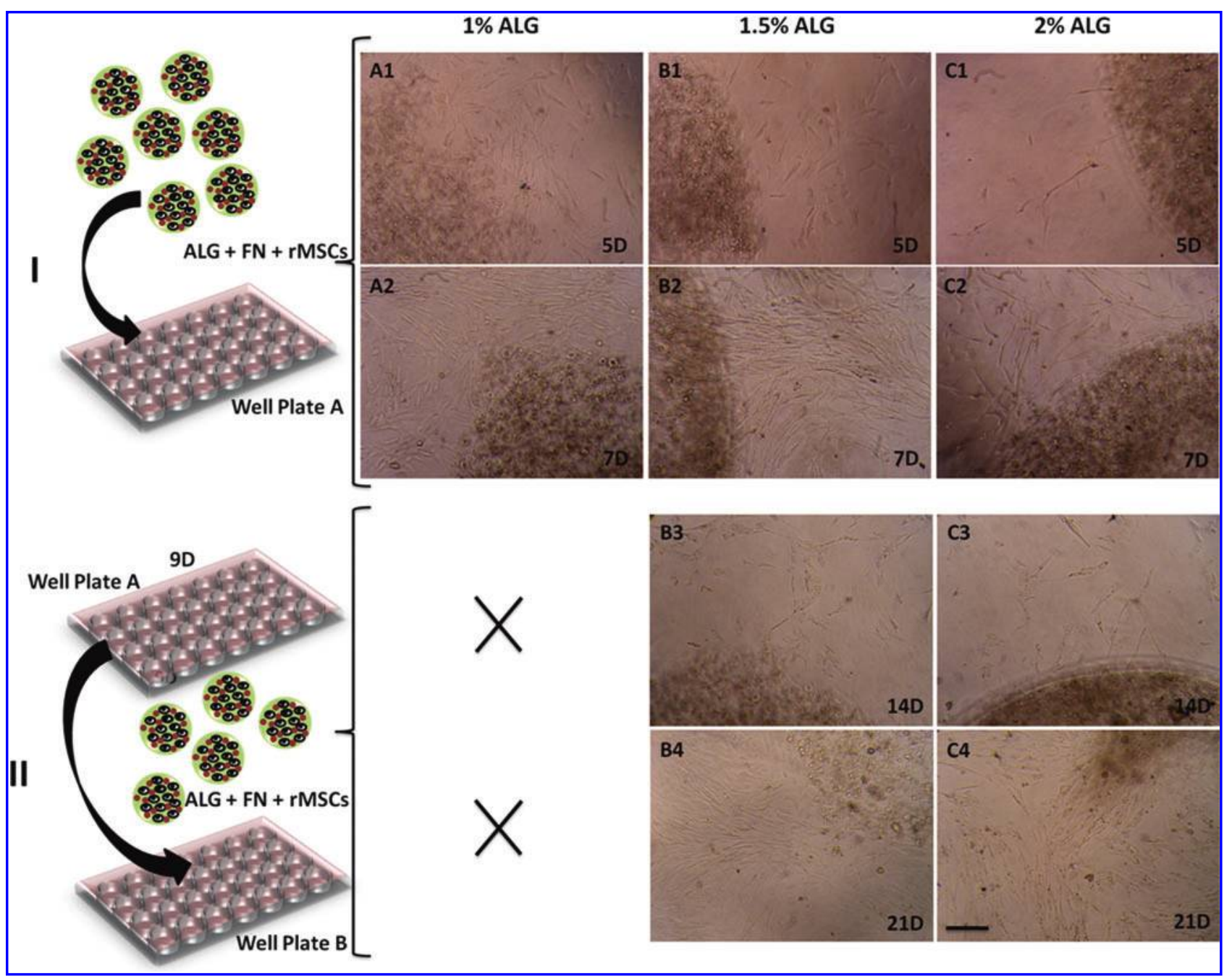

FIG. 7. Part I. The alginate particles with rMSCs + FN were cultured in a well plate for 9 days and the rMSC morphology was accessed by optical microscopy: (A) correspond to 1\% ALG, (B) to 1.5\% ALG, and (C) to 2\% ALG after 5 days (A1, B1, C1) and 7 days (A2, B2, C2) in culture. Part II. When the released rMSCs reach the confluence in the surface of the well plate, the particles were transferred for a new plate. 1\% ALG beads were not transferred because were completely disintegrated before day 9. The other alginate formulations were cultured for more days and the continuous rMSC release was observed at day 14 (B3, C3) and 21 (B4, C4). Scale bar $20 \mu \mathrm{m}$. Color images available online at www.liebertpub.com/tea 


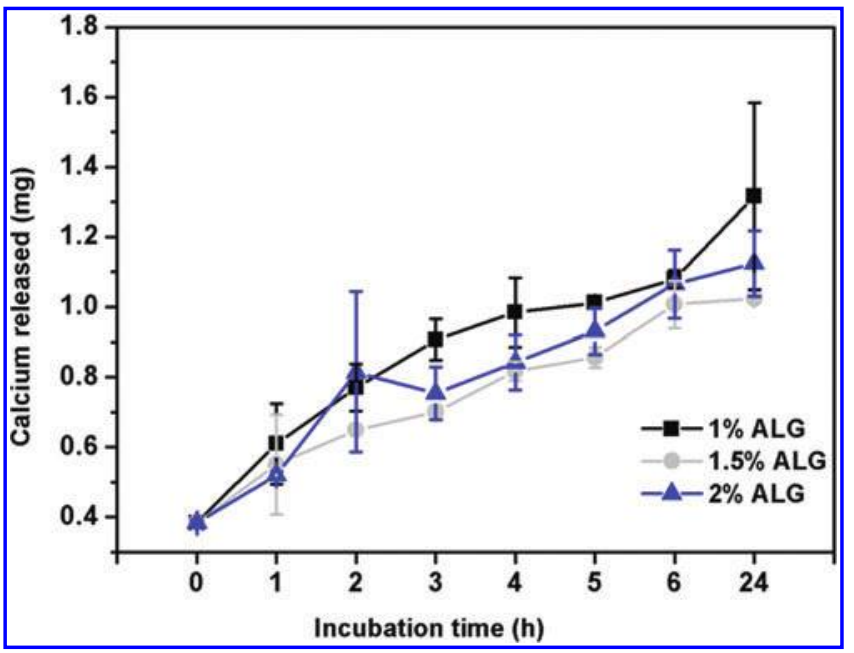

FIG. 8. Cumulative release of calcium ions from alginate beads $\left(1 \%, 1.5 \%\right.$, and $2 \%$ ALG) crosslinked with $\mathrm{CaCl}_{2}$ after immersion in cell culture medium. The calcium at $0 \mathrm{~h}$ corresponds to the amount content in cell culture medium. Color images available online at www.liebertpub.com/tea

the presence of fibroblasts and that lowering the alginate concentration from $5 \%$ to $1 \%$ increased the rate of disintegration. The degradation of the alginate beads structure could be explained by crosslinked chain disintegration caused by the replacement of calcium cations (responsible for the crosslinking) by monovalent cations such as sodium or potassium present in cell culture medium. ${ }^{43,44}$ This was confirmed by the release calcium studies, in which calcium was released from alginate beads for $24 \mathrm{~h}$ (Fig. 8). Moreover, it was hypothesized by Drury et al. ${ }^{45}$ that ion exchange and the reordering of the alginate chain occur within the first 7 days and stabilize thereafter. In our study the $1 \%$ alginate beads disintegrates completely after 7 days in culture medium, while $1.5 \%$ and $2 \%$ alginate beads (or fragments) remained stable for more than 21 days. However, there was no significant effect on the concentration of alginate and the quantity of calcium ions released within this time period. Moreover, calcium is an essential element and plays a key role in skeletal mineralization. During the bone formation, osteoblasts capture calcium from bloodstream (that has been absorbed previously in the intestine or resulted from osteoclasts activity) and deposit it in an appropriate site in the form of calcium phosphate complexes. ${ }^{46}$ Regarding this, it is possible that the in situ calcium delivered may help the mineralization process during bone defect regeneration.

Another important parameter is the number of the cells immobilized inside the beads because studies reported that cell density must be sufficiently high to provide cell contact and consequently the proliferation. ${ }^{38}$ Based on that, about 10,000 cells were encapsulated in beads with $\sim 2 \mathrm{~mm}$. Other studies reported the use of particles containing cells with similar dimensions. Alginate beads with 3.6, 2.2, and $1 \mathrm{~mm}$ were produced for cell encapsulation and used as components of calcium phosphate cements and polymer pastes. ${ }^{41}$ The purpose of these beads is that they could quickly degrade and release the cells throughout the entire scaffolds. However, a considerable part of alginate beads produced so far did not present fast degradable properties and cell release
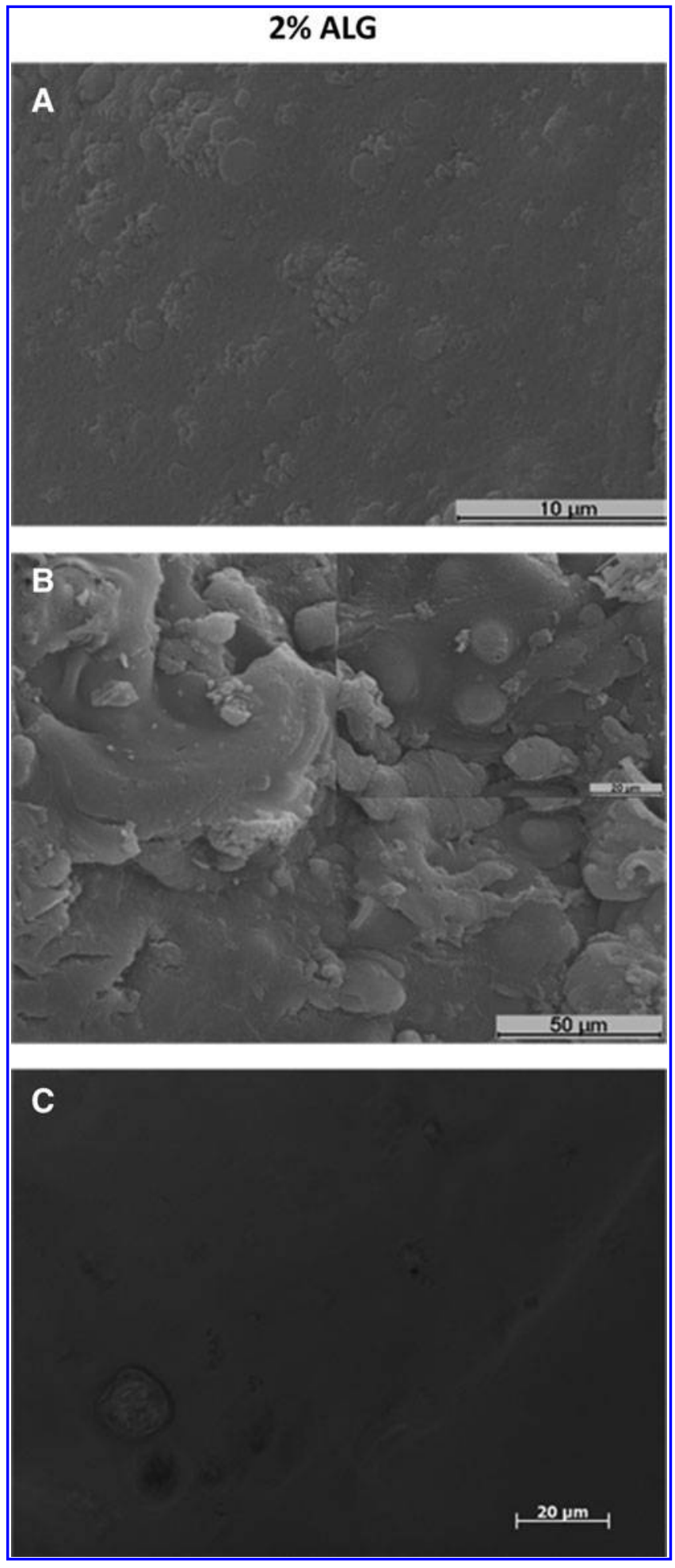

FIG. 9. Scanning electron microscopy micrographs of $2 \%$ ALG + FN without rMSCs (A); with rMSCs immobilized (B), after $48 \mathrm{~h}$ in culture. (C) Corresponds to fluorescent microscopy images of rMSCs stained with Hoechst 33342 immediately after immobilization in $2 \%$ ALG $+F N$. 
was not observed. Zhou and $\mathrm{Xu}^{47}$ reported that it is desirable to have beads with a fast degradation profile in order to promote a quick stem cells release, differentiation, and consequently enhance production of new tissue. Having this into account, it was expected that the fast release of the rMSCs over time and their adhesion into a defect site allowed a continuous and faster regeneration of the damaged tissue.

Due to the higher stability of $2 \%$ ALG +FN beads, this formulation was selected to pursue the studies.
The SEM analysis revealed that $2 \%$ ALG beads without cells (Fig. 9A) present a smooth surface structure. The alginate beads loaded with cells exhibit several protuberances with almost $10 \mu \mathrm{m}$ diameter, which may be caused by the presence of rMSCs immobilized inside the hydrogel (Fig. 9B). To complement this assay, the rMSC nuclei were stained and the immobilized cells were observed through a fluorescent microscope (Fig. 9C). The images showed that cells were inside alginate hydrogels and even on surface having a

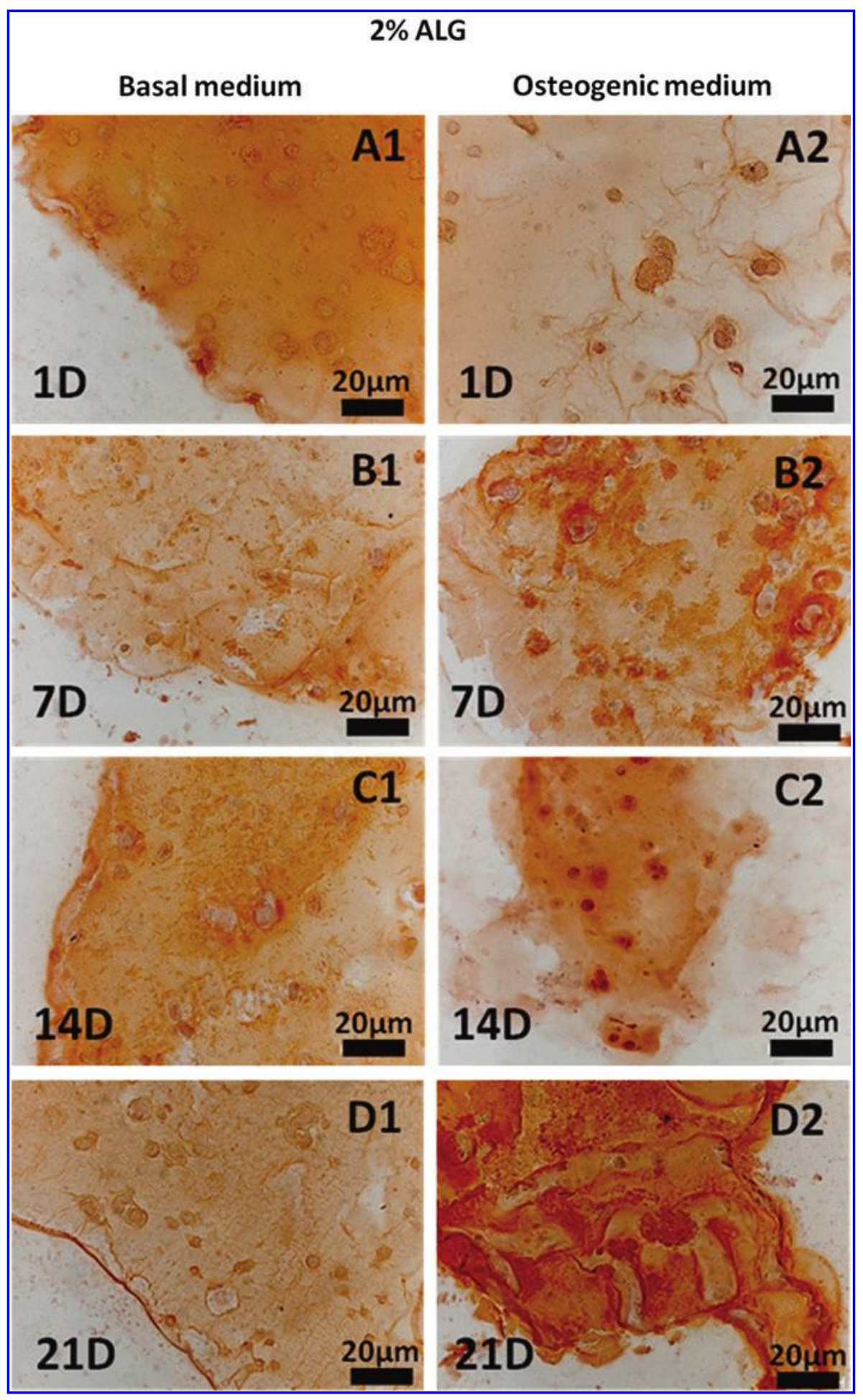

FIG. 10. Alizarin red staining of $2 \%$ ALG + FN + rMSCs after 1 (A1 A2), 7 (B1, B2), 14 (C1, C2), and 21 days (D1, D2) in culture under basal and osteogenic conditions. Color images available online at www.liebertpub.com/tea 
typical round shape. These results corroborate those obtained by SEM analysis.

\section{Osteogenic differentiation assay}

Bone regeneration is a complex physiologic process that includes cell recruitment and proliferation of progenitor cells followed by its differentiation along osteoblastic lineage, osteoid formation (deposition of ECM components), and finally mineralization. ${ }^{48}$ The matrix mineralization consists in calcium deposits. ${ }^{49}$ Alizarin red staining (Fig. 10), which is a specific dye for calcium detection, ${ }^{50}$ showed a staining increase in $2 \%$ ALG + FN + rMSCs from day 1 to 14 (Fig. 10A2, C2) and especially between day 14 and 21 (Fig. 10C2, D2), when the beads were cultured under osteogenic conditions. The same beads formulation maintained under basal conditions did not show any difference in the color of the staining over time (Fig. 10A1, B1, C1, D1).

The high permeability of alginate beads allowed the creation of an enabling in vitro environment for differentiation of encapsulated rMSCs. Similar results were previously obtained by Abbah et al. ${ }^{51}$ using murine-derived adipose-tissue stromal cells encapsulated in alginate for 21 days.

These results also demonstrate that the produced alginate beads had appropriated diffusion characteristics to allow the entrance of nutrients or other molecules that play an important role in rMSC viability and differentiation.

\section{In vivo bone regeneration}

Wistar rats were used to perform the in vivo studies in order to evaluate the biocompatibility of the carriers with immobilized rMSCs and also their capability in stimulating the regeneration of a bone defect not affected by high mechanical stresses. In all studied groups, no specific inflammation or reactive granulomas were observed in tissues surrounded the site where alginate beads were implanted. Furthermore, no pathological abnormalities were observed in the brain, lung, liver, spleen, heart, and kidney samples.

Representative $\mu \mathrm{CT}$ reconstructions of ex vivo bone explants around the defect regions are shown in Figure 11, 4 weeks postimplantation. In the defects of the control group, where no beads were implanted, is not observed bone tissue growth (see Fig. 11-I). Otherwise, in the group II (Fig. 11-II) where alginate beads loaded with FN were implanted, the $3 \mathrm{D}$ reconstructions show a lower level of bone infiltration compared with group III (Fig. 11-III), where alginate beads loaded with FN and rMSCs were implanted.

Histological analysis was performed in order to confirm the previous described results and also to obtain complementary information related to host response and tissue/ cellular organization (see Fig. 12). The light microscopic examination of decalcified sections showed that in control (group I) and group II, new bone tissue formation inside of the defect was not observed; only fragments of periosteum were present. However, neo bone tissue was formed circumferentially along the defects of group III and a significant amount of new bone tissue was visualized in the central areas. In addition, the histology results show an active periosteum and osteoblasts deposition which formed circular structures that give rise to circular pieces of bone tissue (black arrows in Fig. 12-III) without connection to the border of the defect. The presence of osteoclastic-like cells was not visualized as also reactive or granulomatous inflammatory reactions in the surround tissue and fibrous connective tissue in the local where beads were implanted. This supports the local and systemic histocompatibility of these beads. These last results showed that the presence of cells induced the

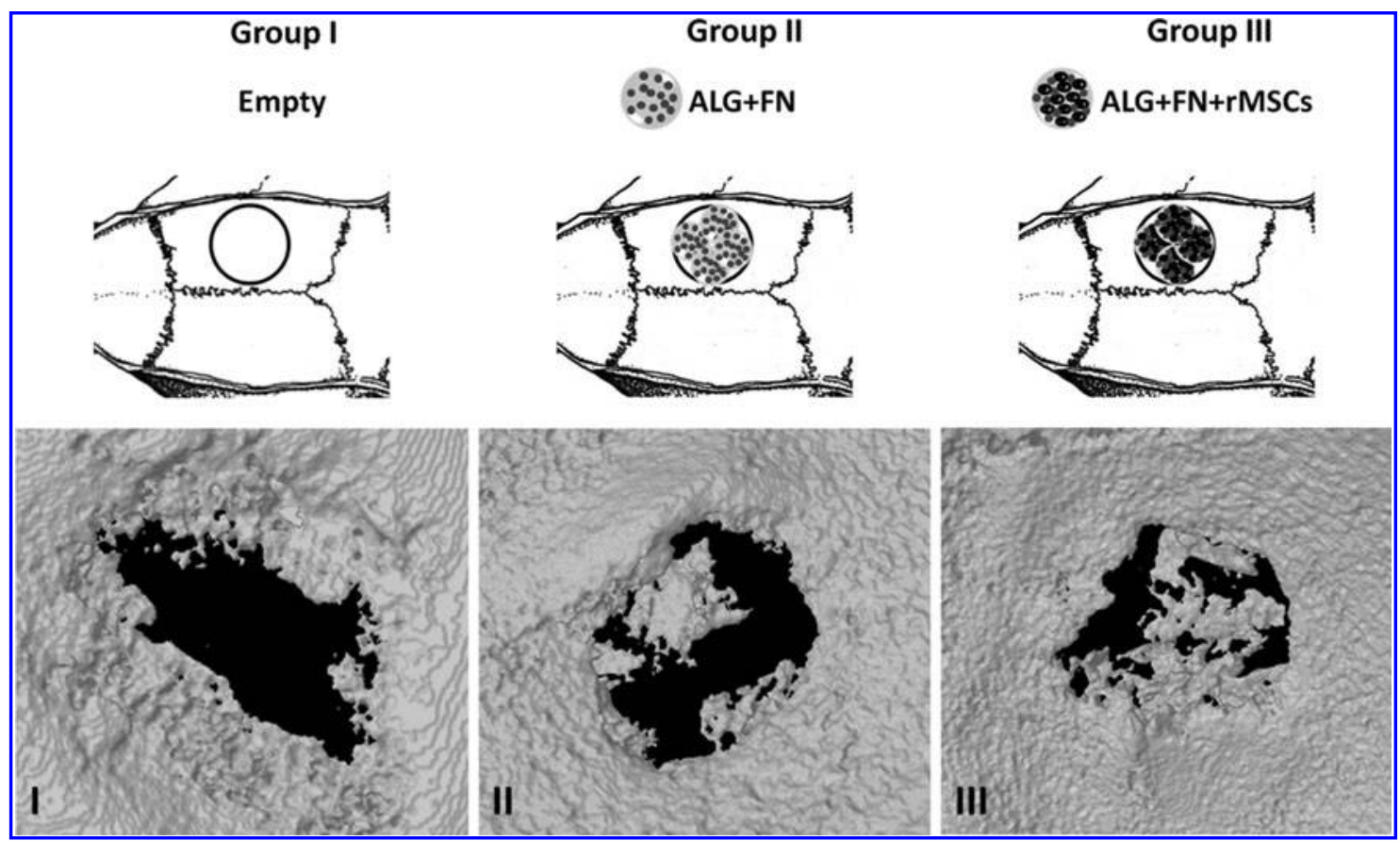

FIG. 11. Microcomputed tomography analysis of calvaria defects in Wistar rats. Images show the endpoint result after 4 weeks of bone regeneration of empty defects (I) and upon implantation of $2 \%$ ALG beads (II) loaded with FN and (III) loaded with FN and rMSCs. 


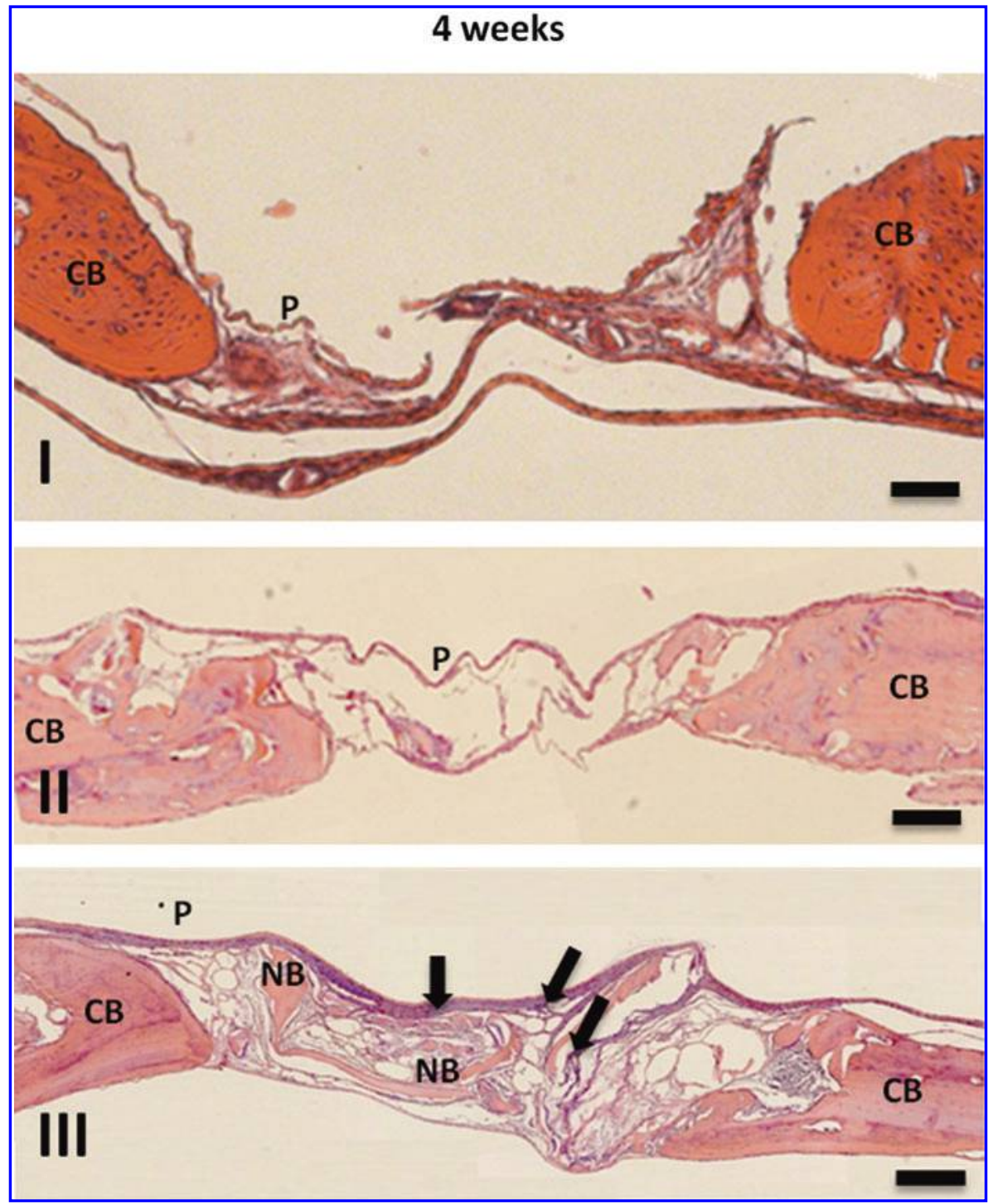

FIG. 12. Hematoxylin and eosinstained histological images of calvaria defects at 4 weeks: empty control group (I), defects filled with beads loaded with FN (II), and beads loaded with FN and rMSCs (III). The black arrows represent the deposition of osteoblasts and formation of circular bone pieces. $\mathrm{CB}$, compact bone; NB, new bone; $\mathrm{P}$, periosteum. Scale bar $200 \mu \mathrm{m}$. Color images available online at www.liebertpub.com/tea

growth of higher amount of new bone tissue after 4 weeks. Furthermore, the visualized deposition of osteoblasts (black arrows in Fig. 12-III) could be correlated with the release of rMSCs by alginate beads, which in turn had the appropriated diffusion properties to allow the differentiation of rMSCs under osteogenic conditions. On the other hand, the differentiated cells released or even the ones remained inside the particles could have delivered key proteins (e.g., growth factors), ${ }^{52,53}$ which recruited other cells to the damaged site and consequently accelerate the tissue regeneration.

Lee et $a l .{ }^{54}$ demonstrated that calcium crosslinked alginate beads mineralized when injected subcutaneously or implanted intramuscularly after 1-6 months during which bone-like apatite deposits were found throughout the microparticles. This information reinforce that alginate is a very interesting material to induce biomineralization and also confirms its application for regeneration of bone damaged tissue.

Taking into account these results, the immobilization of rMSCs with a component of ECM, namely FN, in alginate hydrogels using superhydrophobic surfaces constitute an interesting strategy to obtain particles for cell encapsulation and delivery and to improve tissue regeneration in a cheap, fast, and efficient way.

\section{Conclusion}

The present work evaluated the efficiency of an innovative methodology for the encapsulation of unstable bioactive molecules and cell immobilization in hydrogel spheres to be used in tissue engineering strategies. The use of superhydrophobic PS substrates allowed the production of biocompatible calcium crosslinked alginate beads with viable rMSCs entrapped. This methodology avoided important disadvantages exhibited by conventional encapsulation techniques, such as mechanical forces, particles aggregation, cell and bioactive molecules loss, and wet conditions.

The application of the hybrid alginate beads for bone regeneration was evaluated under in vitro and in vivo conditions, and the results showed that the synergy effect between FN and rMSCs was crucial for bone regeneration. The ALG beads have good permeability for nutrients and $\mathrm{O}_{2}$, which provides to the cells optimal conditions to survive for at least 
21 days. In addition, the encapsulation of the cells allowed their fixation in a proper site of the damaged tissue, avoiding the possibility of cells being removed by the blood stream. Moreover, the rMSCs were released at the same time of alginate degradation, constituting an advantage since it allowed the continuous bone regeneration without cell loss.

\section{Acknowledgments}

The authors acknowledge the financial support of the Portuguese Foundation for Science and Technology (PTDC/ EME-TME/103375/2008 and PTDC/EBB-BIO/114320/2009) for the PhD fellowship to Ana Catarina Lima (SFRH/BD/ 71395/2010), A. Sofia Silva (SFRH/BD/51584/2011), and Patricia Batista (SFRH/BD/45511/2008).

\section{Disclosure Statement}

No competing financial interests exist.

\section{References}

1. Ma, H.-L., Hung, S.-C., Lin, S.-Y., Chen, Y.-L., and Lo, W.-H. Chondrogenesis of human mesenchymal stem cells encapsulated in alginate beads. J Biomed Mater Res A 64A, 273, 2003.

2. Steinert, A., Weber, M., Dimmler, A., Julius, C., Schütze, N., Nöth, U., Cramer, H., Eulert, J., Zimmermann, U., and Hendrich, C. Chondrogenic differentiation of mesenchymal progenitor cells encapsulated in ultrahigh-viscosity alginate. J Orthop Res 21, 1090, 2003.

3. Pittenger, M.F., Mackay, A.M., Beck, S.C., Jaiswal, R.K., Douglas, R., Mosca, J.D., Moorman, M.A., Simonetti, D.W., Craig, S., and Marshak, D.R. Multilineage potential of adult human mesenchymal stem cells. Science 284, 143, 1999.

4. Pereira, D.R., Silva-Correia, J., Caridade, S.G., Oliveira, J.T., Sousa, R.A., Salgado, A.J., Oliveira, J.M., Mano, J.F., Sousa, N., and Reis, R.L. Development of gellan gum-based microparticles/hydrogel matrices for application in the intervertebral disc regeneration. Tissue Eng Part C Methods 17, 961, 2011.

5. Costa, N.L., Sher, P., and Mano, J.F. Liquefied capsules coated with multilayered polyelectrolyte films for cell immobilization. Adv Eng Mater 13, B218, 2011.

6. Hu, M., Kurisawa, M., Deng, R., Teo, C.-M., Schumacher, A., Thong, Y.-X., Wang, L., Schumacher, K.M., and Ying, J.Y. Cell immobilization in gelatin-hydroxyphenylpropionic acid hydrogel fibers. Biomaterials 30, 3523, 2009.

7. Vermonden, T., Fedorovich, N.E., van Geemen, D., Alblas, J., van Nostrum, C.F., Dhert, W.J.A., and Hennink, W.E. Photopolymerized thermosensitive hydrogels: synthesis, degradation, and cytocompatibility. Biomacromolecules 9, 919, 2008.

8. Orive, G., Hernandez, R.M., Gascon, A.R., Calafiore, R., Chang, T.M.S., Vos, P.D., Hortelano, G., Hunkeler, D., Lacik, I., Shapiro, A.M.J., and Pedraz, J.L. Cell encapsulation: promise and progress. Nat Med 9, 104, 2003.

9. Hunt, N., and Grover, L. Cell encapsulation using biopolymer gels for regenerative medicine. Biotechnol Lett 32, 733, 2010.

10. Joki, T., Machluf, M., Atala, A., Zhu, J., Seyfried, N.T., Dunn, I.F., Abe, T., Carroll, R.S., and Black, P.M. Continuous release of endostatin from microencapsulated engineered cells for tumor therapy. Nat Biotechnol 19, 35, 2001.

11. Chang, T.M.S. Therapeutic applications of polymeric artificial cells. Nat Rev Drug Discov 4, 221, 2005.
12. Silva, G.A., Ducheyne, P., and Reis, R.L. Materials in particulate form for tissue engineering. 1. Basic concepts. J Tissue Eng Regen Med 1, 4, 2007.

13. Oliveira, M.B., and Mano, J.F. Polymer-based microparticles in tissue engineering and regenerative medicine. Biotechnol Prog 27, 897, 2011.

14. Mano, J.F., Silva, G.A., Azevedo, H.S., Malafaya, P.B., Sousa, R.A., Silva, S.S., Boesel, L.F., Oliveira, J.M., Santos, T.C., Marques, A.P., Neves, N.M., and Reis, R.L. Natural origin biodegradable systems in tissue engineering and regenerative medicine: present status and some moving trends. $\underline{\mathrm{L}}$ Soc Interface 4, 999, 2007.

15. Grellier, M., Granja, P.L., Fricain, J.-C., Bidarra, S.J., Renard, M., Bareille, R., Bourget, C., Amédée, J., and Barbosa, M.A. The effect of the co-immobilization of human osteoprogenitors and endothelial cells within alginate microspheres on mineralization in a bone defect. Biomaterials 30, 3271, 2009.

16. Endres, M., Wenda, N., Woehlecke, H., Neumann, K., Ringe, J., Erggelet, C., Lerche, D., and Kaps, C. Microencapsulation and chondrogenic differentiation of human mesenchymal progenitor cells from subchondral bone marrow in Caalginate for cell injection. Acta Biomater 6, 436, 2010.

17. Bidarra, S.J., Barrias, C.C., Barbosa, M.A., Soares, R., and Granja, P.L. Immobilization of human mesenchymal stem cells within RGD-grafted alginate microspheres and assessment of their angiogenic potential. Biomacromolecules 11, 1956, 2010.

18. Goren, A., Dahan, N., Goren, E., Baruch, L., and Machluf, M. Encapsulated human mesenchymal stem cells: a unique hypoimmunogenic platform for long-term cellular therapy. FASEB J 24, 22, 2010.

19. Hernández, R.M., Orive, G., Murua, A., and Pedraz, J.L. Microcapsules and microcarriers for in situ cell delivery. Adv Drug Deliv Rev 62, 711, 2010.

20. Mosahebi, A., Wiberg, M., and Terenghi, G. Addition of fibronectin to alginate matrix improves peripheral nerve regeneration in tissue-engineered conduits. Tissue Eng 9, 209, 2003.

21. Tsai, K.-S., Kao, S.-Y., Wang, C.-Y., Wang, Y.-J., Wang, J.-P., and Hung, S.-C. Type I collagen promotes proliferation and osteogenesis of human mesenchymal stem cells via activation of ERK and Akt pathways. J Biomed Mater Res A 94A, $673,2010$.

22. Alsberg, E., Anderson, K.W., Albeiruti, A., Franceschi, R.T., and Mooney, D.J. Cell-interactive alginate hydrogels for bone tissue engineering. J Dental Res 80, 2025, 2001.

23. Augst, A.D., Kong, H.J., and Mooney, D.J. Alginate hydrogels as biomaterials. Macromol Biosci 6, 623, 2006.

24. Lima, A.C., Sher, P., and Mano, J.F. Production methodologies of polymeric and hydrogel particles for drug delivery applications. Expert Opin Drug Deliv 9, 231, 2012.

25. Khademhosseini, A., and Langer, R. Microengineered hydrogels for tissue engineering. Biomaterials 28, 5087, 2007.

26. Song, W.L., Lima, A.C., and Mano, J.F. Bioinspired methodology to fabricate hydrogel spheres for multi-applications using superhydrophobic substrates. Soft Matter 6, 5868, 2010.

27. Lima, A.C., Song, W.L., Blanco-Fernandez, B., AlvarezLorenzo, C., and Mano, J.F. Synthesis of temperature-responsive dextran-MA/PNIPAAm particles for controlled drug delivery using superhydrophobic surfaces. Pharm Res 28, 1294, 2011.

28. Xu, S., De Becker, A., Van Camp, B., Vanderkerken, K., and Van Riet, I. An improved harvest and in vitro expansion 
protocol for murine bone marrow-derived mesenchymal stem cells. J Biomed Biotechnol 2010, 105940, 2010.

29. Wang, Y., Liu, J., Xu, C., Zhang, W., Bai, L., Li, N., Liu, Y., Wang, Y., Su, Y., and Hu, D., Bone marrow transplantation combined with mesenchymal stem cells induces immune tolerance without cytotoxic conditioning. J Surg Res 171, e123, 2011.

30. Soleimani, M., and Nadri, S. A protocol for isolation and culture of mesenchymal stem cells from mouse bone marrow. Nat Protoc 4, 102, 2009.

31. Novikova, L.N., Mosahebi, A., Wiberg, M., Terenghi, G., Kellerth, J.-O., and Novikov, L.N. Alginate hydrogel and matrigel as potential cell carriers for neurotransplantation. J Biomed Mater Res A 77A, 242, 2006.

32. Coimbra, P., Alves, P., Valente, T.A.M., Santos, R., Correia, I.J., and Ferreira, P. Sodium hyaluronate/chitosan polyelectrolyte complex scaffolds for dental pulp regeneration: synthesis and characterization. Int J Biol Macromol 49, 573, 2011.

33. Fotakis, G., and Timbrell, J.A. In vitro cytotoxicity assays: comparison of LDH, neutral red, MTT and protein assay in hepatoma cell lines following exposure to cadmium chloride. Toxicol Lett 160, 171, 2006.

34. Jin, C., Kaewintajuk, K., Jiang, J., Jeong, W., Kamata, M., Kim, H.-S., Wataya, Y., and Park, H. Toxoplasma gondii: a simple high-throughput assay for drug screening in vitro. Exp Parasitol 121, 132, 2009.

35. Vater, C., Kasten, P., and Stiehler, M. Culture media for the differentiation of mesenchymal stromal cells. Acta Biomater 7, 463, 2011.

36. Franco, C.L., Price, J., and West, J.L. Development and optimization of a dual-photoinitiator, emulsion-based technique for rapid generation of cell-laden hydrogel microspheres. Acta Biomater 7, 3267, 2011.

37. Tai, B.C., Wan, A.C., and Ying, J.Y. Modified polyelectrolyte complex fibrous scaffold as a matrix for 3D cell culture. Biomaterials 31, 5927, 2010.

38. Herrero, E.P., Valle, E.M.M.D., and Galán, M.A. Immobilization of mesenchymal stem cells and monocytes in biocompatible microcapsules to cell therapy. Biotechnol Prog 23, 940, 2007.

39. Toworfe, G.K., Bhattacharyya, S., Composto, R.J., Adams, C.S., Shapiro, I.M., and Ducheyne, P. Effect of functional end groups of silane self-assembled monolayer surfaces on apatite formation, fibronectin adsorption and osteoblast cell function. J Tissue Eng Reg Med 3, 26, 2009.

40. Keselowsky, B.G., Bridges, A.W., Burns, K.L., Tate, C.C., Babensee, J.E., LaPlaca, M.C., and García, A.J. Role of plasma fibronectin in the foreign body response to biomaterials. Biomaterials 28, 3626, 2007.

41. Zhao, L., Weir, M.D., and Xu, H.H. Human umbilical cord stem cell encapsulation in calcium phosphate scaffolds for bone engineering. Biomaterials 31, 3848, 2010.

42. Hunt, N.C., Shelton, R.M., and Grover, L. An alginate hydrogel matrix for the localised delivery of a fibroblast/ keratinocyte co-culture. Biotechnol J 4, 730, 2009.

43. Hunt, N.C., Smith, A.M., Gbureck, U., Shelton, R.M., and Grover, L.M. Encapsulation of fibroblasts causes acceler- ated alginate hydrogel degradation. Acta Biomater 6, 3649, 2010.

44. Bajpai, S.K., and Sharma, S. Investigation of swelling/ degradation behaviour of alginate beads crosslinked with $\mathrm{Ca} 2+$ and Ba2 + ions. React Funct Polym 59, 129, 2004.

45. Drury, J.L., Dennis, R.G., and Mooney, D.J. The tensile properties of alginate hydrogels. Biomaterials 25, 3187, 2004.

46. Peacock, M. Calcium metabolism in health disease. Clin J Am Soc Nephrol 5, S23, 2010.

47. Zhou, H., and Xu, H.H. The fast release of stem cells from alginate-fibrin microbeads in injectable scaffolds for bone tissue engineering. Biomaterials 32, 7503, 2011.

48. Oreffo, R.O., and Triffitt, J.T. Future potentials for using osteogenic stem cells and biomaterials in orthopedics. Bone 25, 5S, 1999.

49. Martins, A.M., Alves, C.M., Reis, R.L., Mikos, A.G., and Kasper, F.K. Toward osteogenic differentiation of marrow stromal cells and in vitro production of mineralized extracellular matrix onto natural scaffolds. Biological Interactions on Materials Surfaces. New York: Springer, 2009, pp. 263-281.

50. Evangelista, M.B., Hsiong, S.X., Fernandes, R., Sampaio, P., Kong, H.-J., Barrias, C.C., Salema, R., Barbosa, M.A., Mooney, D.J., and Granja, P.L. Upregulation of bone cell differentiation through immobilization within a synthetic extracellular matrix. Biomaterials 28, 3644, 2007.

51. Abbah, S.A., Lu, W.W., Chan, D., Cheung, K.M., Liu, W.G., Zhao, F., Li, Z.Y., Leong, J.C., and Luk, K.D. In vitro evaluation of alginate encapsulated adipose-tissue stromal cells for use as injectable bone graft substitute. Biochem Biophys Res Commun 347, 185, 2006.

52. Keshaw, H., Forbes, A., and Day, R.M. Release of angiogenic growth factors from cells encapsulated in alginate beads with bioactive glass. Biomaterials 26, 4171, 2005.

53. Penolazzi, L., Tavanti, E., Vecchiatini, R., Lambertini, E., Vesce, F., Gambari, R., Mazzitelli, S., Mancuso, F., Luca, G., Nastruzzi, C., and Piva, R. Encapsulation of mesenchymal stem cells from Wharton's jelly in alginate microbeads. Tissue Eng Part C 16, 141, 2010.

54. Lee, C.S., Moyer, H.R, Gittens, R.A, Williams, J.K., Boskey, A.L., Boyan, B.D., and Schwartz, Z. Regulating in vivo calcification of alginate microbeads. Biomaterials 31, 4926, 2010.

Address correspondence to: João F. Mano, PhD

3B's Research Group-Biomaterials, Biodegradables and Biomimetics University of Minho

AvePark, Zona Industrial da Gandra, S. Claudio do Barco Guimarães, Caldas das Taipas 4806-909 Portugal

E-mail: jmano@dep.uminho.pt

Received: April 19, 2012

Accepted: December 7, 2012

Online Publication Date: February 14, 2013 